\title{
Problems and Issues Related To Mother of an Only Child in India
}

\author{
Disha Chaudhari ${ }^{1}$
}

\section{ABSTRACT}

In a nation like INDIA where 'Chieftain' is very important word with every one, it is a hard challenge for a mother to grow their children even if she is having family to support her. Many parents get confused about having a single child or more than one. They generally facing some questions like 'Never have just one child!', 'Are only children happier?', “The Best Reasons for Having More Than One Child” and many more. They often get confused about deciding whether have a single child or more that they could not decided what is better for their child. So this article is all about the problems and its solution related to single child and her mother as parent.

Keywords: Mother related Issues, Child, India

Parents generally think that having only one child is much easier for them than having two or more children. But in actual it is a fact that they are having a more difficult time because the onus of entertaining the child falls entirely on the parents. As I researched, I see many parents who decided to have only one child, and they seem awfully peaceful! They often give lots of attention to the one child, which means that the only child must feel extremely loved and attended to.

Having only one child also allows the parent to be more used to the individual emotional needs of the single child because there isn't another child whose needs take the parent away from the other child. The fact that the parents of only children have more time and energy to become and stay attuned to the child shouldn't be overlooked, because attunement to the emotional needs of a child is crucial for positive emotional and cognitive development in children kids often feel that their strongest ally and most trusted partner in the family system is their sibling or siblings even if they sometimes fight and insist that they dislike each other. So mother as a parent of only child need to make a strong relation in between her and her child that child does not feel alone in the relation.

As a working mother of a single child it is a tough job for her to give equal time to her work and her family with a good care to her child. It is always been an issue for working mother to give valuable time when child actually needed it because she cannot neglect her work as well.

\footnotetext{
${ }^{1}$ M. A. psychology, North Gujarat University, Mehsana, Gujarat (C) 2015 I D Chaudhari; licensee IJIP. This is an Open Access Research distributed under the terms of the Creative Commons Attribution License (http://creativecommons.org/licenses/by/2.0), which permits unrestricted use, distribution, and reproduction in any Medium, provided the original work is properly cited.
} 
It is also a fact that a couple who having only child they always need to think about their child but in actual situation working parents make the kid conform to their life not the other way or not the way child wants to be. It is always been a problem for a single child that he sounds more like an over controlled little adult person that most of his day time he has to be with his work at school or alone at home or with one parent alternatively.

Mothers as a parent of a single child they must choose to live a life style that is child oriented not more adult oriented because child with no siblings is always totally dependent on their parents. Mother in the family always thinks to have a sibling for her child to share all sorts of problems with.

As family is important to the socialization of children, it plays an important role in the development of children's intellect and personality Western scholars Toni Falbo and Denis F. Polit (1986) have noted the three discrete discrepancies between only children and children with siblings.

- First, children with siblings often exchange amongst each other their respective academic and social experiences - an advantage that single-children lack.

- Second, single-children tend to be dominated more by self-seeking instincts, commanding more attention in their individual homes.

- Third, because parents tend to treat their single-child the way standard parents treat their first-born (with more vigilance and care due to inexperience), single-children will generally be more reliant on their parents and less independent.

Compare to children with siblings of the same age single children have superior It could be that parents of only-children tend to demonstrate higher care and caution when raising their children - to the point that such children often adopt a more active and enthusiastic stance toward grouporientated activities.

In other words, the most important factors in any child's development are not whether they have a brother or a sister, but whether their parents have a good education and adopt the right values for the family. It is unavoidable that only-children will have experience certain things differently from children with siblings. Also, it is often believed that because only children and their parents often share a higher level of intimacy, their parents will be more attentive to the needs of their children; they would make a greater effort to maintain good relations and be more supportive toward their children's personal and academic endeavors.

Researchers at China's Center for Children Development showed in the 1980's that parents of only-children, on the whole, have a higher level of expectation for their children's career and academic achievements. Mercy and Steelman (1982) have also reported that only-children spend more time with their parents than do non-only children. Lewis and Feiring (1982) have also found that single-children are more inclined to communicate with their parents, often with greater confidence and versatility in their conversations. 
Furthermore, many single children often lack a means to channel their stress (as they don't have a close sibling-confident), which might lead to long-term problems. The type of pressure placed on only children by their parents might lead to irrevocable consequences, and only gradual communication and societal modifications (such as increased organized social affairs) might lead to the amelioration of such issues. This may not be as easy as it seems.

However, it is undeniable that single children will create a different society for China. And for the betterment of that society, we must first enhance single children's opportunities and abilities at social communication, interaction, and development.

There's no better peer to learn from than a sibling. It's the first person you have to share with, starting with mom and dad. Whether the little one watches the older sister negotiate another piece of cake after dinner, or they both have regular knock-down drag-out fights, this is the relationship that gets you ready for the real world.

\section{CONCLUSION:}

In the end of this article I suggest some of the point that will help mothers of a single child in a way that both enables and encourages. That way the child will be able to develop their personality and not be overly impinged by the adult worst they find themselves in.

- As your child is an only child to your family let him be a child only don't expect more from him, don't give him responsibilities that he need to be a 'little adult'

- Mother should not tell her child that you are not going to spoil them because you will probably make them feel they are losing out.

- As a only child in family, mother is a closest person to child with whom child like to share all his experiences, feelings, liking and disliking. So make them feel you can say anything to me as

- am your mother, It is being a problem for mother to give time for her child as he Is almost living alone if mother is doing job.

- Encourage your child to join groups etc so they can interact with lots of different children with interests similar to theirs.

- Don’t overprotect your child or expect too much independence too early.

- Encourage your child to take responsibility for aspects of their life and be aware that many only children feel overly responsible for their parents well being.

- Remember your child will be much more sensitive to your needs than you may imagine so let them know you have a life outside of them.

- Make your child sometimes wait for things they want, or you will set up expectations of instant gratification which is hard for them to unlearn once they have relationships.

- Don't encourage your child to be the centre of attention - it can be very painful when they go out into the real world. 


\section{REFERENCES}

Article on having other child: http://www.onlychild.org.uk/2015/06/22/when-having-anotherchild-is-not-an-option-yet-families-are-still-sterotyped-as-selfish/

Article on negative side of having one child : http://www.onlychild.org.uk/2015/05/26/a-followon-from-the-negative-side-of-having-one-child/

Myths on having child: http://content.time.com/time/magazine/article/0,9171,2002530,00.html

Single child families: http://www.dailymail.co.uk/debate/article-2299634/Single-child-familiesepidemic-loneliness.html 